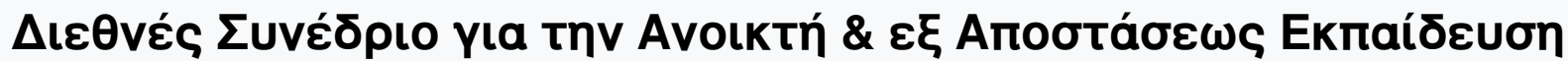

Tóp. 7, Ap. 2A (2013)

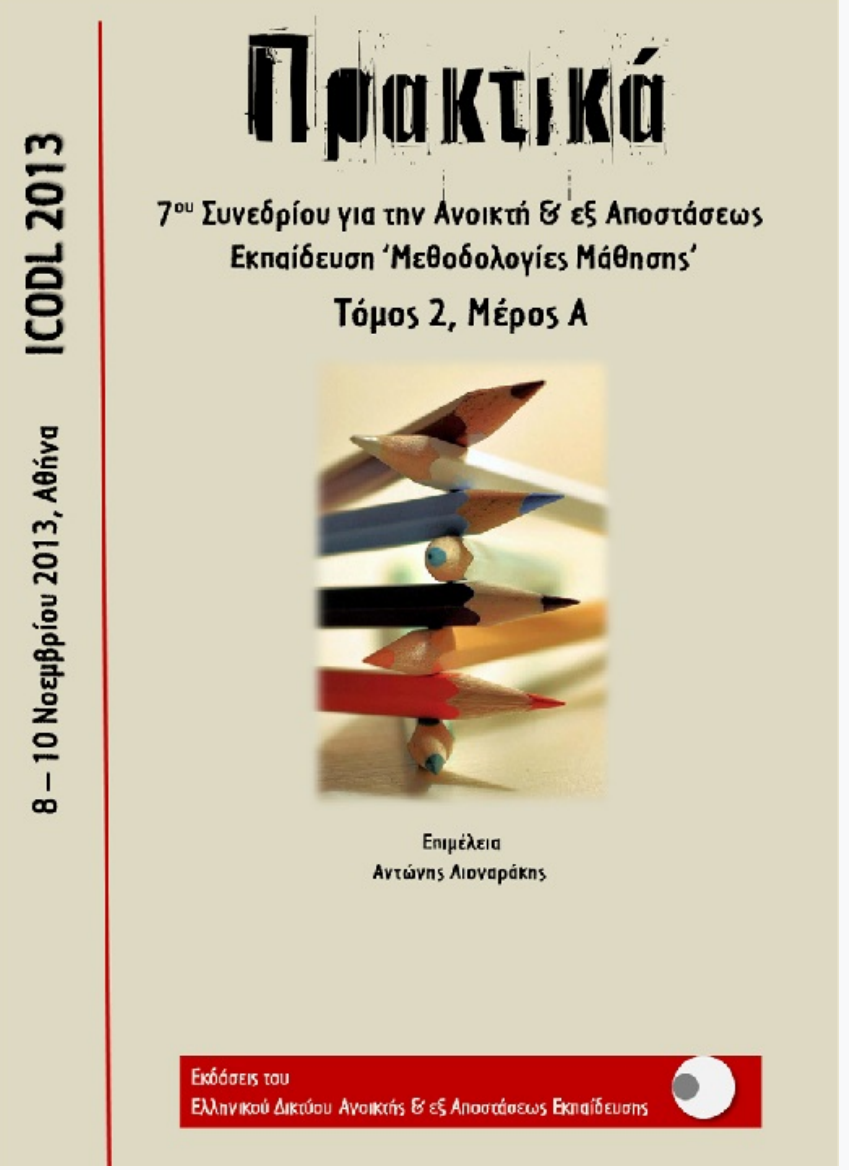

A pilot e-tutoring program for first and second grade students of lower secondary education (Gymnasio)

Spyros Doukakis, Cleo Koutroumpa, Theodora Chira, Georgia Michalopoulou

doi: $\underline{10.12681 / \text { icodl. } 570}$ 


\title{
A pilot e-tutoring program for first and second grade students of lower secondary education (Gymnasio)
}

\author{
Spyros Doukakis \\ The American College of Greece-PIERCE \\ sdoukakis@acg.edu
}

Theodora Chira

The American College of Greece-PIERCE tchira@acg.edu
Cleo Koutroumpa

The American College of Greece-PIERCE cleo@acg.edu

Georgia Michalopoulou

The American College of Greece-PIERCE gmihalopoulou@acg.edu

\begin{abstract}
58 first and second grade students of lower secondary education (Gymnasio) participated in a pilot e-tutoring program on ancient Greek and mathematics that was implemented during the school year 2012-2013. Two teachers for each subject provided daily two hour support to students. The program was realized through Blackboard Collaborate and was focusing on the support of students who a) wanted to redefine and/or meditate and/or probe on issues raised during the morning school courses or b) were absent during morning school courses. In this paper are presented the results of a research conducted using a questionnaire answered by the students involved in the program after the latter's completion.

The results show that 6 out of 10 students participated in e-tutoring sessions. Their satisfaction exceeded 90\%, while the program's acceptance exceeded $94 \%$. Furthermore, the students who didn't participate in it declared that this was mainly because they didn't need it. Also, in the study no correlations between gender, personal involvement with web 2.0 tools and knowledge of computer use were observed. Finally, the students related their satisfaction to the e-tutor's role as a facilitator, something that puts forward the need for further investigation of the educator's role.
\end{abstract}

Keywords: e-tutoring, secondary education, satisfaction

\section{Introduction}

The integration and incorporation of digital tools to the educational procedure has led educators to the redefining of their way of teaching, while at the same time has increased researchers' and educators' interest in pin-pointing appropriate methods for the utilization of these tools in supporting students' learning. Within this framework, e-tutoring (electronic tutoring or online tutoring) is a digital media of supporting students, which utilizes possibilities offered by the internet and web 2.0 tools in order to enhance the cooperation between students and educators.

E-tutoring has the characteristics of traditional teaching in a classroom. In this sense, there is a teacher that facilitates students to acquire further knowledge, develop capacities and modify attitudes towards the subject taught (Corrigan, 2012). The difference lies on the environment through which the cooperation between teacher 
and student is realized. E-tutoring is realized through an online environment, where an internet site or platform is used (Johnson \& Bratt, 2009). E-tutoring environments dispose a series of interactional and co-operational possibilities that contribute to teaching, learning and students assessment. Furthermore, these environments provide a synchronous discussion system which permits face to face contact in rooms, dispose a multifunctional whiteboard with graphics, chat, application sharing, students' assessment tools, and offer the possibility of recording the e-tutoring course for further and later use, etc. (Blackboard Inc., 2012). Finally, taking into consideration the easy access to and use of Blackboard Collaborate, as well as the fact that teachers and students are at home and not at their work place (or wherever they wish, for that matter), e-tutoring environments modify students', teachers' and parents' perspective of teaching and learning.

In this paper, at first, is presented the frame of e-tutoring utilization in the international and Greek educational community. In the next section, the pilot operation of the e-tutoring program in the school is described. Sequentially, the research conducted on the students is reported and the data and relative descriptive measures, followed by the research's results, are presented. Finally, the paper concludes with the outcome and discussion on issues of e-tutoring implementation, whilst ideas for future research are cited.

\section{Overview}

The increase of internet use and the integration of web 2.0 tools to the educational procedure has led to the growing utilization of e-tutoring environments. According to the pertinent literature, e-tutoring is an individualized service providing support to a student or a group of students from an educator who uses the internet as their mean of communication (Flowers, 2007; Johnson \& Bratt, 2009; Corrigan, 2012). Even though e-tutoring and e-learning have common characteristics as far as online communication is concerned, the student's task in e-tutoring environments is additional to the material taught during the morning course, in contrast to e-learning where the student has specific obligations (Corrigan, 2012).

Researcher Prensky (2003) supports that e-tutoring can function more effectively than traditional teaching, due to the frequency of interaction, the immediate feedback and the personal style of teaching and learning. Lately, e-tutoring is offered internationally by public, private, and non-profit institutions (George \& Dykman, 2009). A case of integrated e-tutoring is the "Homework Help" program which was created in 2008 by the Ontario Ministry of Education. In 2011 it covered about 236.000 students. The program (https://homeworkhelp.ilc.org/) functions providing free synchronous etutoring by Ontario certified mathematics teachers to students in Grades 7 to 10. The students can connect to the Homework Help site and receive support from an educator five evenings per week.

According to Jopling's research (Jopling, 2011), several studies of e-tutoring programs have been published, but only 17 of them offer empirical data. From these, 8 have been realized in the USA, 3 in England, 2 in Canada, 1 in Spain, 1 in Scotland, 1 in Mexico and 1 in Australia. From these 17 studies, 11 concern exclusively primary and secondary education. Furthermore, 9 out of the 11 study the possible improvement of the students' school performance. Particularly, from the studies is shown a) the greater students' involvement in the learning procedure (Pinder, 2008) when they participate in an e-tutoring program, b) the possibility provided to educators to take into consideration their students' style of learning and thinking and to students to bring forth their interests (Hastie et al., 2007) and c) the opportunity 
provided to educators and students to use pedagogical tools which couldn't be utilized in the traditional classroom (Balajthy et al., 2001). On top of that, from the research of Dekhnet et al. (2008) is shown that through e-tutoring the students further develop their initial motives for learning, as their involvement in the program modifies their perspective of learning. According to the results of the Beal et al. research (2007), most benefited was the weakest student of the group that participated in the e-tutoring program. Finally, Gabriel kaı Kaufield (2008) put forward that teaching through an etutoring environment provides "bidirectional learning opportunities" for both the educator and the student and contributes to the student's participation in a community of learning, reinforcing students that were isolated in the traditional teaching and learning environment.

However, in the Greek educational community no studies related to e-tutoring environments in primary and secondary education have been recorded. Thus, in this paper we will try to show the way the available e-tutoring environment within the educational unit was utilized and, sequentially, the research conducted to students who used e-tutoring as an educational procedure, as well as its results.

\section{Operation frame of e-tutoring program}

The e-tutoring platform that was used in the educational unit is Blackboard Collaborate (BC). The software is offered through a browser and allows for online conferences. It has been designed to support participative synchronous meetings and to promote communication. Anyone wishing to, can connect to the platform, as long as $\mathrm{s} / \mathrm{he}$ has a computer with a connection to the internet and an internet address. The environment is presented in Figure 1.

At first, the students were trained for 6 school hours at the environment and the available tools, while it was discussed between e-tutors and students the way to utilize and the netiquette for appropriate use of the e-tutoring program. The students were notified that they needed at least a microphone and speakers or headphones with a speaker. Furthermore, a palette with ancient Greek letters, which were not provided by the platform but were deemed necessary, was created for the teaching of ancient Greek, while mathematics teachers were able to use the dynamic mathematical software Geogebra.

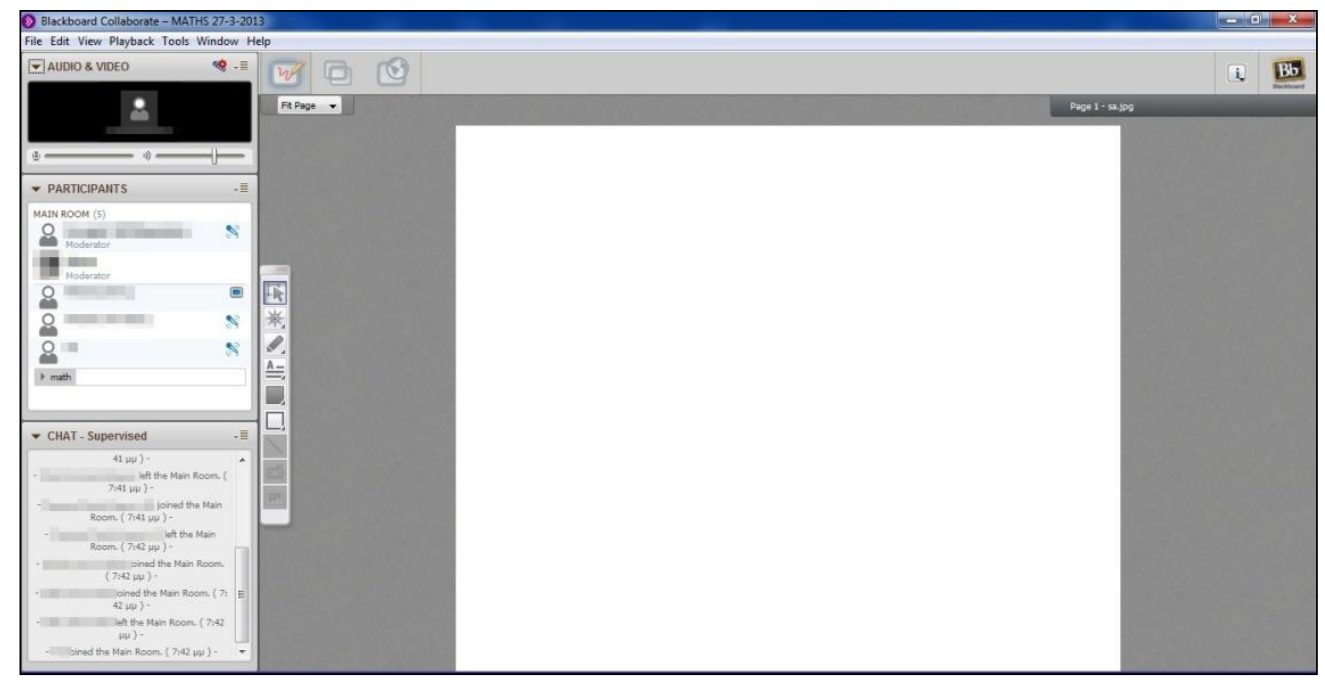

Figure 1. Blackboard Collaborate platform 
Daily each student received two internet addresses (one for ancient Greek and one for mathematics) and was able to connect to e-tutoring of the subject s/he wished. The pilot operation of the program lasted seven weeks, during the first of which students' training was realized. E-tutoring was available for 2 hours per day, 4 evenings per week, for 28 first graders and 30 second graders students of lower secondary education (Gymnasio).

The digital tools used for teaching were various. Mostly, suitable PowerPoints presentations uploaded on Whiteboard through an appropriate tool available from Blackboard Collaborate. (Figure 2).

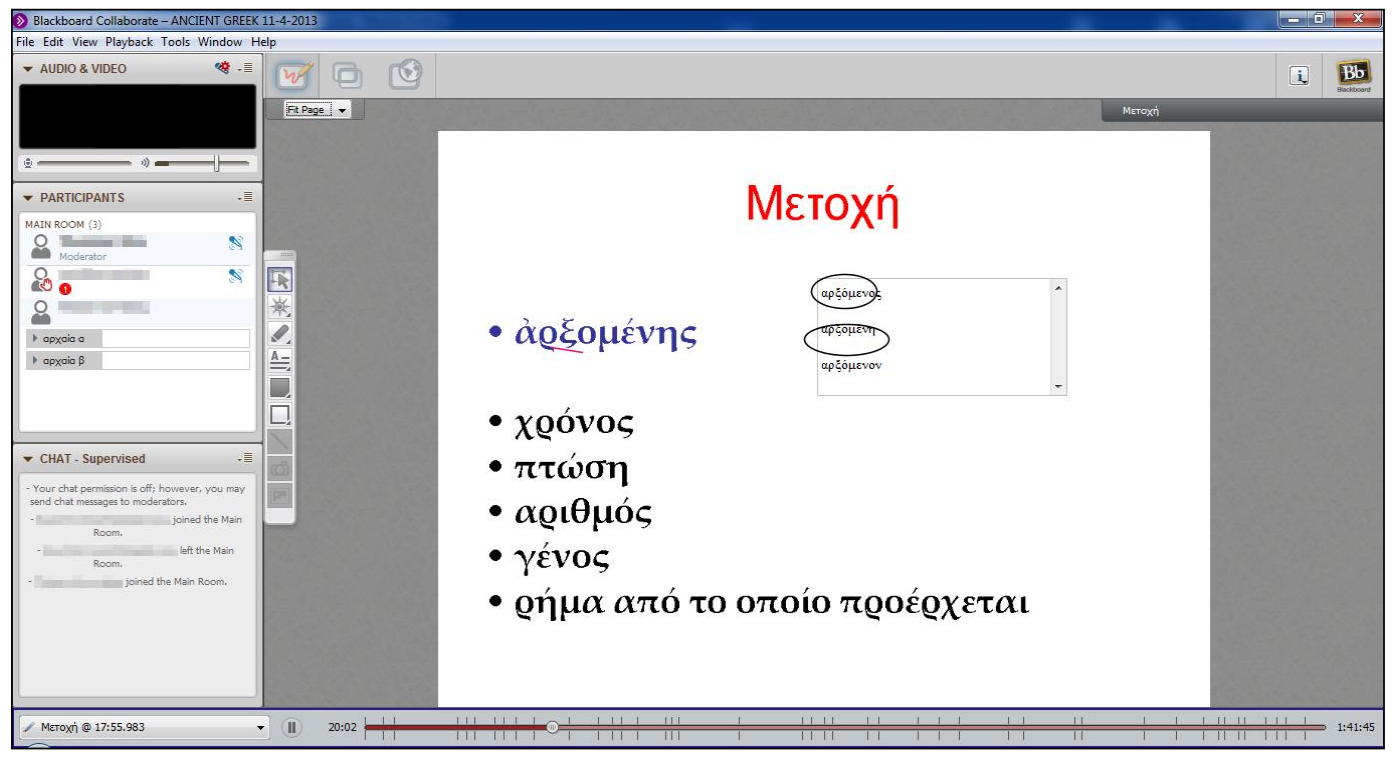

Figure 2. PowerPoint uploading on Whiteboard

On PowerPoint presentations students and the e-tutor were able to intervene, adding comments, erasing, marking or underlying.

Furthermore, direct writing on Whiteboard was utilized, using tools from the control panel (Figure 3). Mathematics teachers used the dynamic mathematical software Geogebra, which, through Application Sharing or Print Screen, produced appropriate images (Figure 4). Application Sharing also proved valuable in solving problems on technical matters. Along those, the possibility to assess students through wrong/right answers and multiple choice questions was applied. Finally, particularly useful proved the possibility to divide groups of students into private working rooms. All e-tutoring courses were recorded, in order for them to be available both to students and educators. 


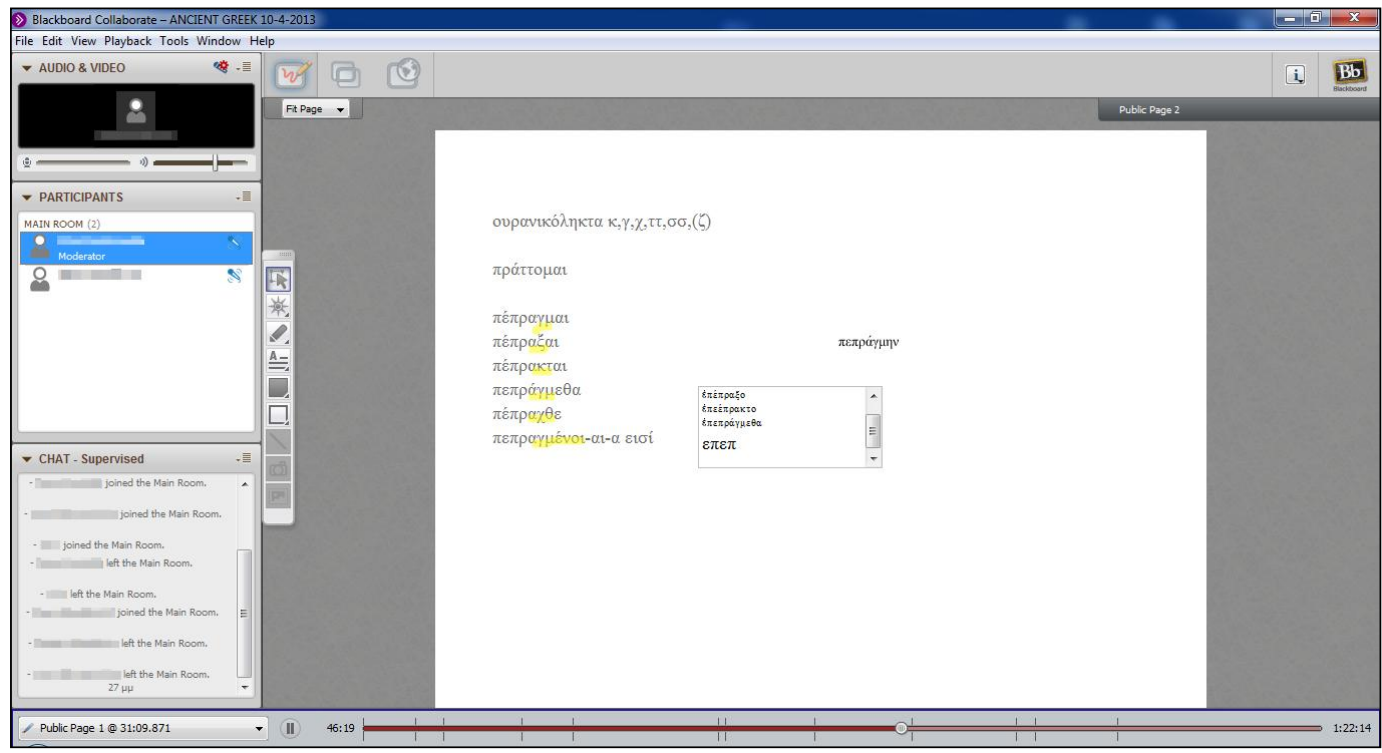

Figure 3. Utilization of Whiteboard

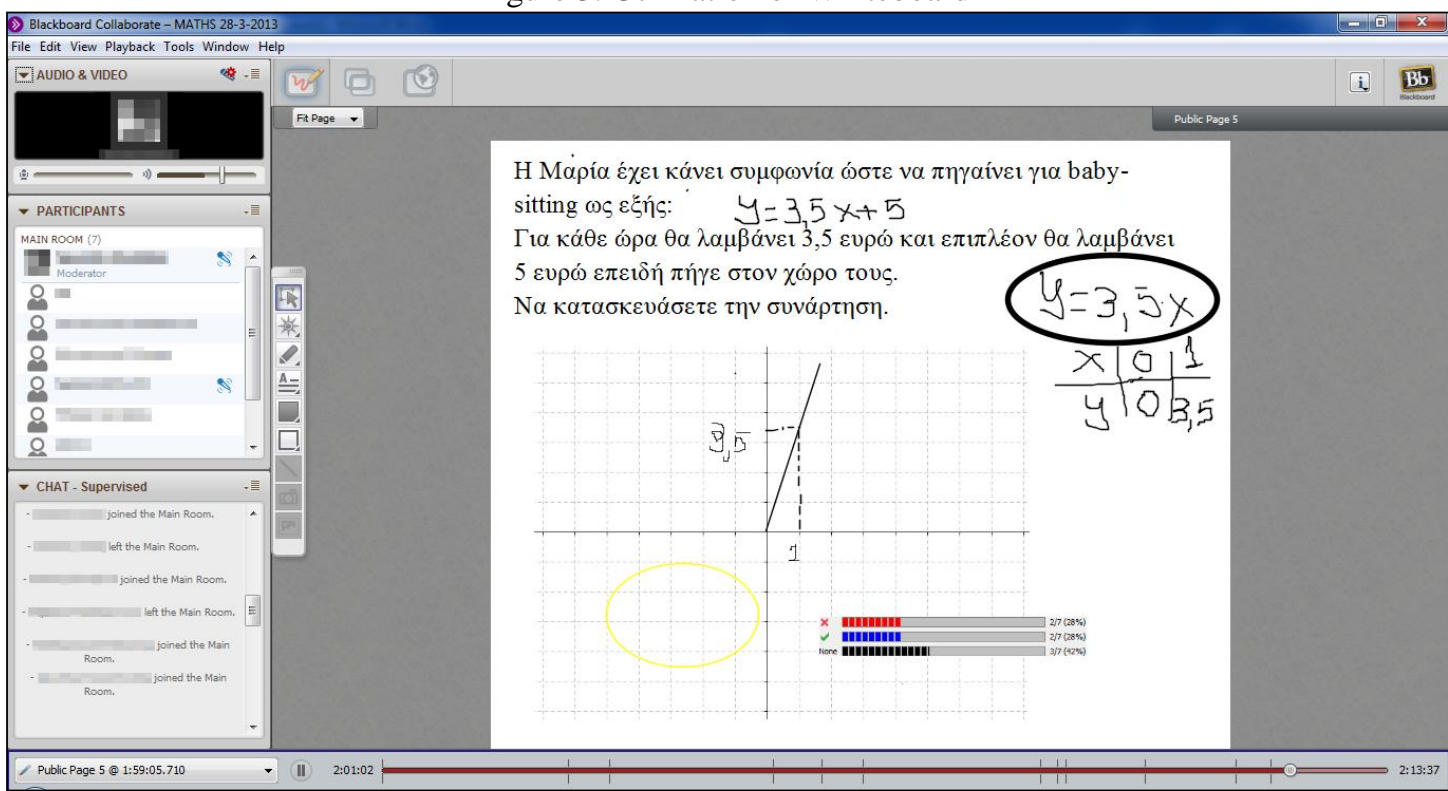

Figure 4. Students' assessment through e-tutoring

During the pilot operation of the program, students' participation ranged from 0 to 15 students per two-hour session. The duration of their "stay" on the program ranged from 10 minutes to 2 hours. Nonetheless, sometimes the program lasted more than two hours, since there were open discussions between the e-tutor and his/her students. Overall, 22 e-tutoring meetings for every subject and 137 students' connections were occurred.

With the completion of the program's pilot operation, students were asked to fill anonymously a questionnaire in order to a) research the degree of their satisfaction from e-tutoring, b) research whether through the e-tutoring program they gained in their learning, c) research the reasons for which some students didn't use the program and d) relate their answers to gender, grade, knowledge of computer, internet and web 2.0 tools use. 


\section{Research approach}

A survey questionnaire was used in this study. It consisted of two sections; the first section required that participants provide demographic and educational information (gender, grade, knowledge of computer use and internet, existence of a Facebook account and/or use of Skype program), and the second section included items which measure the degree of students' satisfaction from the whole program and the learning benefits they might have gained from it. Satisfaction has been defined as the perception of pleasurable fulfillment of a service (Oliver, 1999). For the development of the questionnaire, questions adapted from previous studies were used (Corrigan, 2012; Siritongthaworn \& Krairit, 2006; Shee \& Wang, 2008).

The questionnaire was distributed to the students after the completion of the pilot operation. Initially it was given to two students (a boy and a girl) who were asked to complete it, in order to track down any problems. From the two students, the one, even though s/he was given the chance, did not use e-tutoring. The responses to the questionnaire from the two students showed no misunderstandings. Then, the questionnaire was filled out by the total of students that had the possibility to use etutoring. 58 questionnaires were completed. Students connected at least once to etutoring were asked to answer other questions as well, concerning the way of communication during the use of e-tutoring, the degree of satisfaction from the environment, the e-tutors and the material. The questionnaire is included in the appendix of the present paper.

The data gathered was analyzed with SPSS software. With its use, both the descriptive statistics of data and the correlations were measured, as well as the reliability analysis (Cronbach's alpha), in order to evaluate the level of internal consistency of its elements.

\section{Results}

\section{Descriptive statistics}

In the research participated 58 students (28 from first and 30 from second grade of lower secondary education (Gymnasio)). 33 (57\%) of the participants were boys and $25(43 \%)$ were girls. The students were originally asked if they possess a Facebook and/or Skype account and, furthermore, were asked to define their knowledge on computer and Internet use. From the whole number of students asked $50(86 \%)$ have a Facebook account, while $34(59 \%)$ have a Skype account.In table 1 the profile of the research students is presented.

\begin{tabular}{|c|c|c|c|}
\hline & Students' profile & No & $\%$ \\
\hline Gender & $\begin{array}{l}\text { Male } \\
\text { Female }\end{array}$ & $\begin{array}{l}33 \\
25\end{array}$ & $\begin{array}{l}57 \% \\
43 \%\end{array}$ \\
\hline Grade & $\begin{array}{l}1^{\text {st }} \text { grade } \\
2^{\text {nd }} \text { grade }\end{array}$ & $\begin{array}{l}28 \\
30\end{array}$ & $\begin{array}{l}52 \% \\
48 \% \\
\end{array}$ \\
\hline
\end{tabular}

As far as the knowledge of computer use and internet is concerned, the results of the data analysis are shown in Figure 5 and Figure 6. According to the research results, 45 students declared excellent or very good knowledge of computer use, whilst 11 declared good or average knowledge ( 2 students didn't answer). Also, 54 students declared excellent or very good, while 4 declared good knowledge of internet use. 


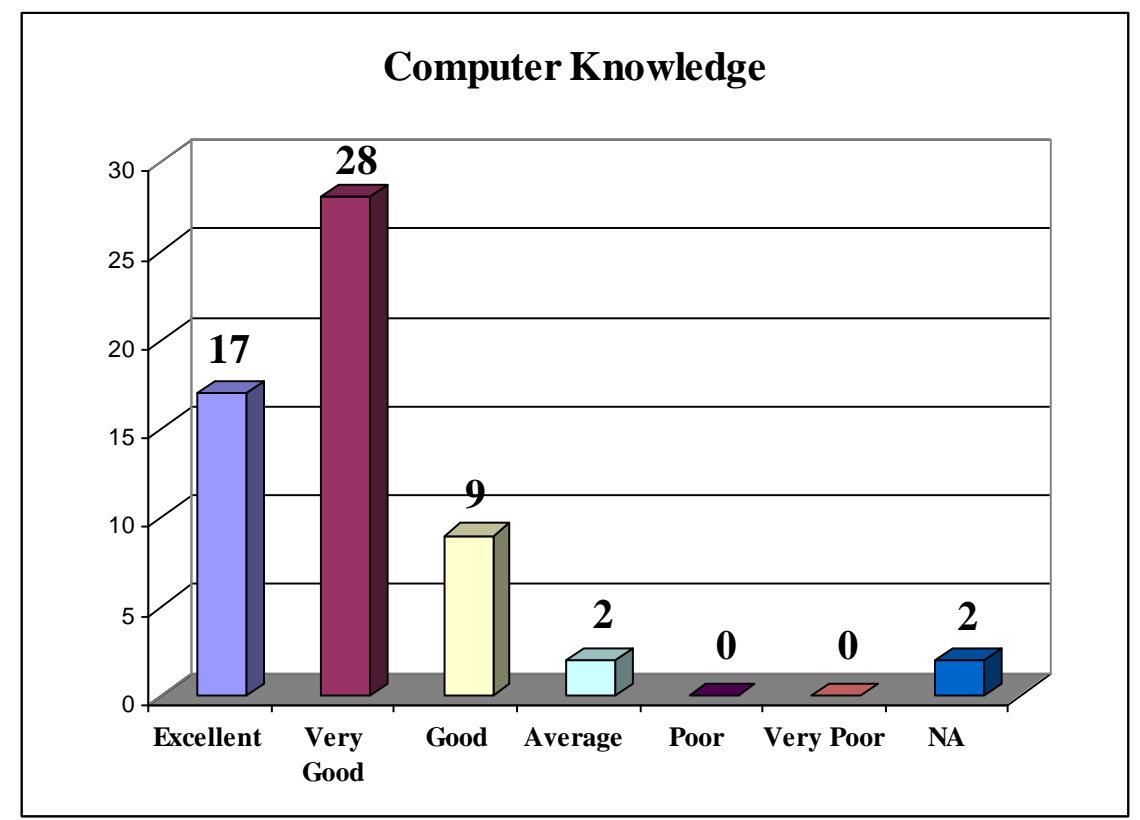

Figure 5. Participants' computer knowledge

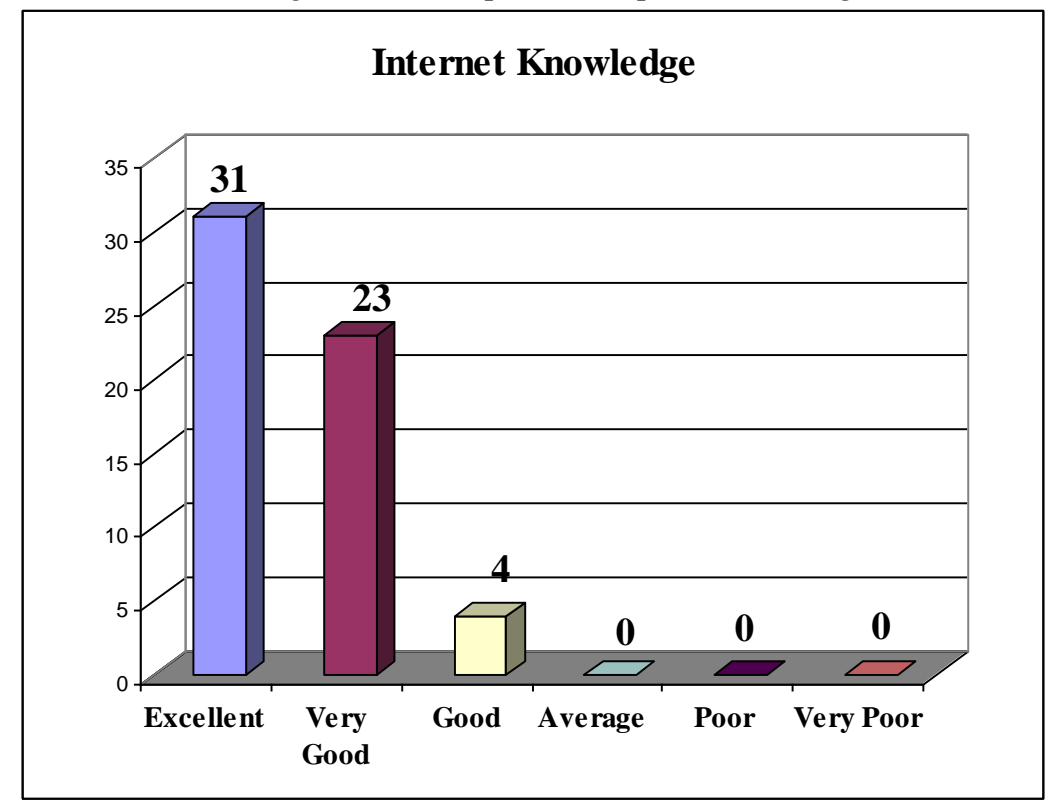

Figure 6. Participants' Internet knowledge

From the research results and the study of the recorded meetings is shown that 23 students $(39,6 \%)$ didn't participate or were never connected to the e-tutoring program. From the remaining 35, $15(25,8 \%)$ were connected at least once to both subjects; 9 $(15,5 \%)$ only participated in ancient Greek and $10(17,2 \%)$ only in mathematics sessions. As a sum, 137 students' connections occurred, from which 49 were in ancient Greek and 88 in mathematics.

The 23 students that were not connected to the e-tutoring program gave several reasons for not doing so. From the results demonstrated on Figure 7, is shown that the most important reason is: "I did not need it in ancient Greek" and "I did not need it in mathematics". 12 students declared that they did not have the time to use it, since they were engaged in other activities during the two-hour period that e-tutoring was available. Furthermore, 5 students faced technical problems (connection or sound 
issues), whilst 4 said that they didn't like it. Finally, 2 students couldn't use etutoring, because, as they said, they didn't have a computer.

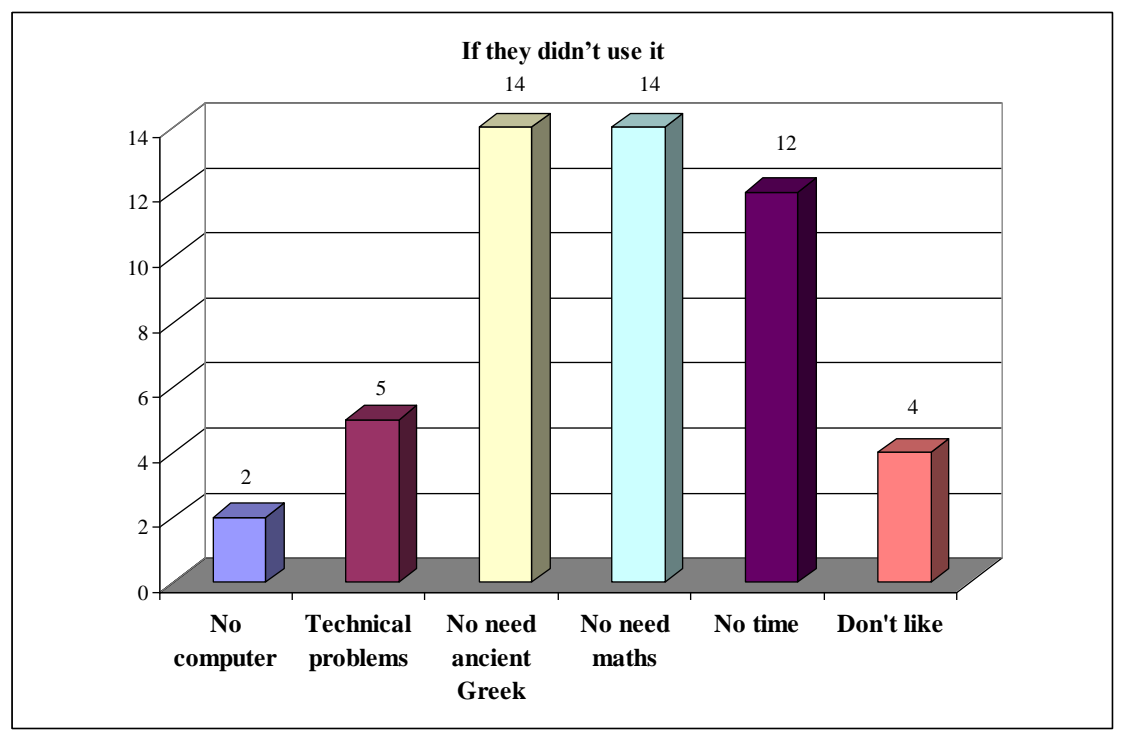

Figure 7. The reasons for not using e-tutoring

From the total number of participants, only students connected at least once to etutoring were called upon to answer questions concerning the environment and the educational procedure in which they took part. Even though the original range of questions included the following possible answers "I totally agree", "I agree", "I neither agree nor disagree", "I disagree", "I totally disagree", "I don't know/ no answer", finally the answers were grouped into four variables: the variable "I agree" where "I totally agree" and "I agree" were included, the variable "I disagree" where "I disagree" and "I totally disagree" were included, while remained unchanged the variables", "I neither agree nor disagree" and "I don't know/ no answer".

According to the results, the students in general declared high satisfaction of the program in which they participated. More particularly, 32 out of the 35 students who used the program were satisfied, while 33 out of 35 deemed it successful. (Figure 8).

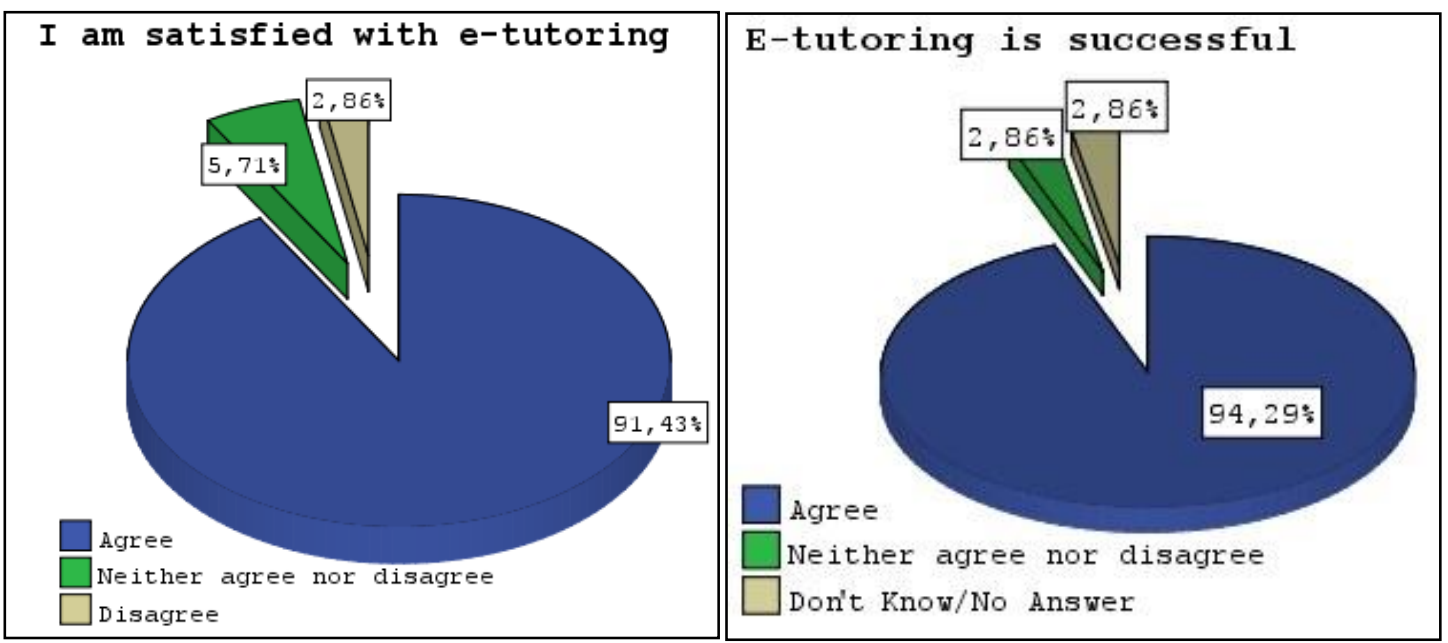

Figure 8. Overall satisfaction of e-tutoring 
At the same time, 28 out of 35 students declared that e-tutoring responded to their needs. On top of that, $80 \%$ of the students declared that through e-tutoring they received individualized support aimed at learning.

As far as the program's environment is concerned, 30 students declared that it was easy to use and 33 that it was friendly (Figure 9). Furthermore, 33 out of 35 students said that the environment was safe.
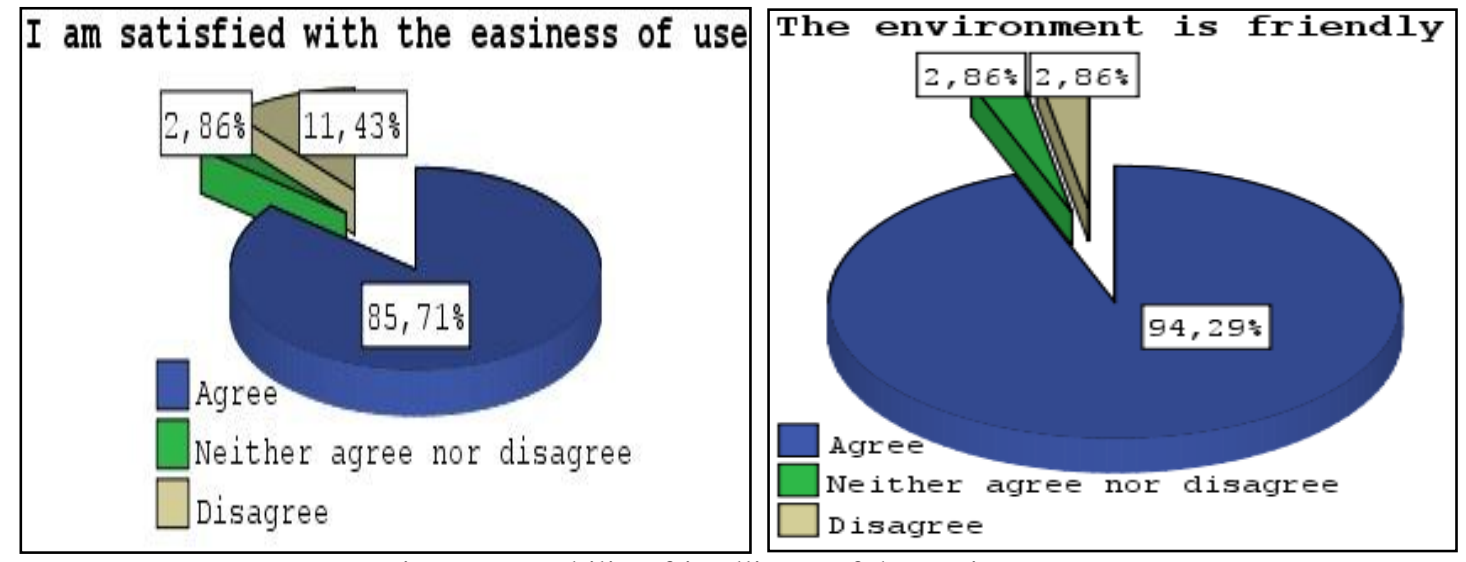

Figure 9. Usability, friendliness of the environment

Also, roughly $89 \%$ of the students declared that through the environment they were provided with the help necessary to master the subject's material. However, only 20 of the 35 students admitted that e-tutoring helped them control the progress of their learning. In this context, a rough $89 \%$ of the students said that through e-tutoring easy communication between the e-tutor and students was developed. Nonetheless, only $52 \%$ of them said that it was easy to communicate with their classmates. Approximately $89 \%$ of the students declared that the material provided through etutoring by the e-tutors responded to their needs and $85 \%$ of them considered this material sufficient. (Figure 10).

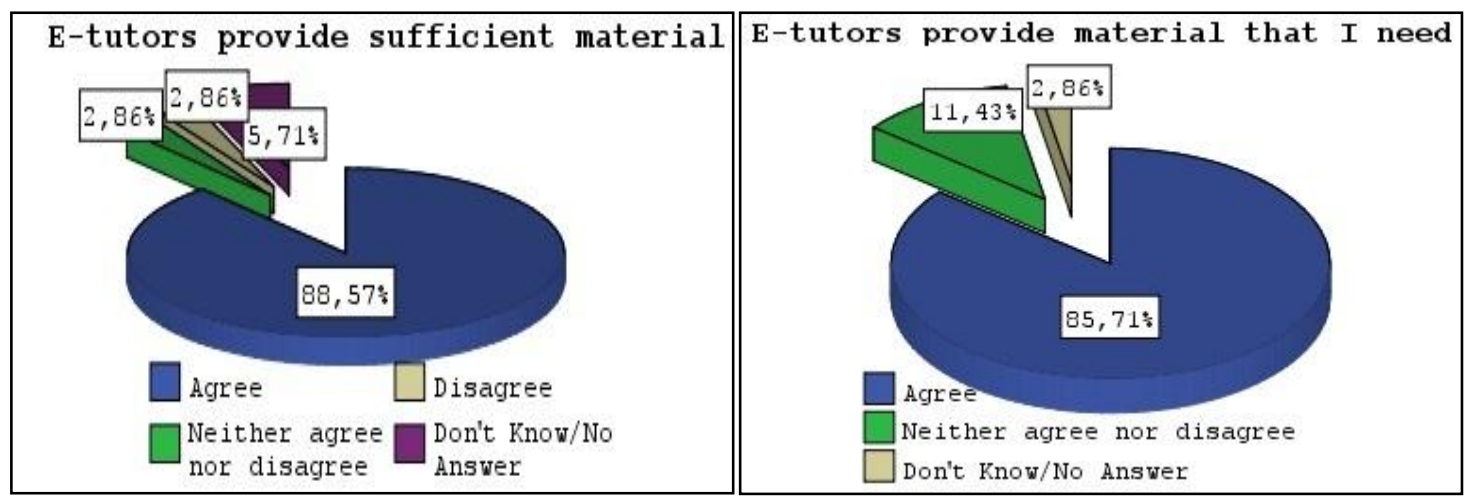

Figure 10. About e-tutors and their material

\section{Reliability analysis}

Regarding the reliability, Cronbach's (1951) alpha indicators' was applied. According to Fornell and Larcker (1981), Cronbach's alpha value greater than 0.7 indicates a high reliability. The result of the test revealed acceptable indices of internal consistency is 0.889 . 


\section{Correlation analysis}

A correlation analysis followed using $\mathrm{X}^{2}$ method, in order to detect substantial statistic differences between the students' assertions. In the analysis the correlation concerning gender, grade, knowledge of computer and Internet use, the possession of Facebook and Skype account was investigated. From the data analysis is demonstrated that there is no apparent correlation between the use of e-tutoring and the level of knowledge of computer and Internet use, nor gender and age.

On the other hand, there seems to be a relation between the student's grade and his/her possession of a Facebook account. There is a significant correlation between the student's grade and his/her procession -according to him/her- of a Facebook account $\left(X^{2}=9.94, D F=1, p=0.002\right)$. It is possible that more second graders than first graders possess Facebook accounts.

\section{Discussion}

E-tutoring programs constitute a contemporary approach to teaching and learning, aiming to the coverage of students' needs. The present research didn't detect statistically important differences between the participants' gender, age and knowledge of computer and Internet use. It appears that the research's students don't have differences as far as the use of both digital environments (Facebook and Skype) and educational environment of e-tutoring are concerned. The results agree with modern researches that refer generally to e-learning environments (Bruestle et al., 2009; Cuadrado-García et al., 2010). According to the above mentioned researches, the differences between boys and girls are rare, since digital environments and new technologies have been integrated in young people's daily routine.

Furthermore, with the excellent and very good knowledge of computer and Internet use, the students didn't face problems with the use of the e-tutoring environment, and, thus, no statistically important differences among the participants in the research were observed.

Also, from the data analysis was shown that that the students' participation in the etutoring program did not depend on the possession of a Facebook and/or Skype account. The small number of students that didn't possess a Facebook account did not utilize at all e-tutoring in mathematics, but they declared that this was because "I did not need it in mathematics".

The results show high student satisfaction and great acceptance of the e-tutoring pilot program. Students' satisfaction and acceptance of similar programs on international level is also high (Cheng et al., 2007). For the students it was an innovative program they hadn't used in the past and the learning benefits they declared that they acquired contributed to the improvement of their school performance. E-tutors provided students with material that met their personal needs, as the students themselves defined them. The students connected to the environment informed the e-tutor of the material of the morning course on which they wished to be supported, and the e-tutor with appropriate presentations and targeted questions, tasks and exercises tried to help students overcome the learning impediments they had spotted. In this context, it was very important that students defined their personal needs, which enhanced their selfawareness concerning the knowledge they had obtained during the morning course or their study at home, as well as the deficiencies they had located and wished to be helped to overcome. Nonetheless, from the research's results it was shown that only 6 out of 10 students thought that e-tutoring helped them control their progress of learning, a fact that demonstrates that the rest of the students considered e-tutoring as a tool that contributes to the overcome of daily learning problems and not to the

Volume 2 - Section A: theoretical papers, original research and scientific articles 
overall improvement of their learning. The above results are in agreement with the Beal et al. (2007) research who state that with e-tutoring programs is succeeded the improvement of some students and especially those with low performances.

Through the environment was reinforced a form of communication between e-tutor and students which is difficult to achieve within the classroom context, since personal contact of each student separately and the meeting of his/her needs was considered important by the students. As a result, they consider crucial the e-tutor's role as a facilitator to overcome the learning obstacles they had located themselves. This role appears also at Brychan et al. (2004) research, where the e-tutor needs to possess special communication, feedback to students and organizational abilities, and at the same time qualitative characteristics, such as enthusiasm, support and reinforcement of students, flexibility and easy access to students.

However, what appears not to have been achieved to a satisfactory degree through the environment was students' cooperation with each other, since only one out of two thought s/he could easily communicate with his/her classmates through e-tutoring. Even though the environment allows students' cooperation, it appeared -according to students- that this possibility (breaking up in rooms and then examining cooperatively the material provided) was not utilized. According to relative bibliography, the achievement of this goal include some actions on the educators part such as the use of open answer questions to students, the participatory communication of students and the designation of conversations conducted on the e-tutors responsibility (Jorge, 2011). Although, during the particular pilot program, the cooperation of students in the Blackboard Collaborate wasn't cultivated, the results might be useful for further discussion.

\section{Conclusion}

The present study was conducted as a pilot implementation of an e-tutoring program on first and second grade students of lower secondary education (Gymnasio). The students declared satisfaction from the program and high acceptance. It appears that during the online support provided to students through the digital environment of etutoring, the students didn't feel they were at a distance from the e-tutor and declared they were supported to overcome their learning impediments. They declared satisfied with the development of a further relationship with e-tutors. Furthermore, they attributed to the e-tutor the role of a facilitator who helped them overcome their learning difficulties.

Further research on the above mentioned directions, will provide elements for the more thorough evaluation of e-tutoring programs. Also important is the examination and documentation of e-tutors' opinions for the e-tutoring program, as well as the knowledge they need to possess in order to offer their students as many learning benefits as possible.

Overall, it appears that e-tutoring programs can provide an alternative way of supporting students' needs, who can gain multiple learning benefits both on knowledge and on abilities and stances.

\section{References}

Balajthy, E., Reuber, K. \& Robinson, C. (2001). Teachers' Use of Technology in a Reading Clinic. Reading Online, 5(3), Available at: http://www.readingonline.org/articles/balajthy/ [Accessed: 10 June 2013].

Beal, R.B., Walles, R., Arroyo, I. \& Woolf, B.P. (2007). On-line tutoring for math achievement testing: a controlled evaluation. Journal of Interactive Online Learning 6, 43-55. 
Blackboard Inc. (2012). Blackboard Collaborate, Delivering ROI for K-12 Schools.

Bruestle, P., Haubner, D., Schinzel, B., Holthaus, M., Remmele, B., Schirmer, D., Reips, U.D. (2009). Doing E-Learning/Doing Gender? Examining the Relationship between Students' Gender Concepts and E-learning Technology. 5th European Symposium on Gender \& ICT Digital Cultures: Participation - Empowerment - Diversity, March 5-7, 2009 - University of Bremen. Available at:

http://www.informatik.unibremen.de/soteg/gict2009/proceedings/GICT2009_Adamus.pdf.[Accessed: 31 July 2009].

Brychan, T., Jones, P., Packham, G., \& Miller, C. (2004). Student Perceptions of Effective Emoderation: A Qualitative Investigation of E-College Wales, Networked Learning Conference. April 5-7, $2004 \quad$ - Lancaster University, Available at: http://www.networkedlearningconference.org.uk/past/nlc2004/proceedings/individual_papers/ thomas_et_al.htm

Cheng, S.S., Liu, Z.F., Ko, H.W. \& Lin, C.H. (2007). Learning with online tutoring: rural area students' perception of satisfaction with synchronous learning. International Journal of Computers and Communications, 1(2), 48-54.

Corrigan, J.A. (2012). The Implementation of E-Tutoring in Secondary Schools: A Diffusion Study. Computers \& Education, 59(3), 925-936.

Cronbach, L.J. (1951). Coefficient alpha and the internal structure of tests. Psychometrika, 16(3), 297334.

Cuadrado-García, M., Ruiz-Molina, M.E., \& Montoro-Pons, J.D. (2010). Are there gender differences in e-learning use and assessment? Evidence from an interuniversity online project in Europe. Procedia Social and Behavioral Sciences, 2(2), 367-371.

Dekhinet, R., Topping, K., Duran, D., \& Blanch, S. (2008). Let Me Learn with My Peers Online: Foreign language learning through reciprocal tutoring. Innovate 4(3).

Flowers, A.T. (2007). NCLB spurs growth in online tutoring options. School Reform News, The Heartland Institute, Chicago, IL. Available at: http://www.heartland.org/Article.cfm?artId=20426.

Fornell, C., Larcker, D.F. (1981). Evaluating structural equation models with unobservable variables and measurement error, Journal of Marketing Research, 48, 39-50.

Gabriel, M.A. \& Kaufield, K.J. (2008). Reciprocal mentorship: an effective support for online instructors. Mentoring \& Tutoring: Partnership in Learning 16, 311-327.

George, B., \& Dykman, C. (2009). Virtual tutoring: the case of TutorVista. Journal of Cases in Information, 3(3), 45-61.

González-Gómez, F., Guardiola, J., Rodriguez, Ó.M., \& Alonso, M.Á.M. (2012). Gender differences in e-learning satisfaction. Computers \& Education, 58(1), 283-290.

Hastie, M., Chen, N. \& Kuo, Y. (2007). Instructional design for best practice in the synchronous cyber classroom. Educational Technology \& Society, 10, 281-294.

Johnson, G.M., \& Bratt, S.E. (2009). Technology education students: e-tutors for school children. British Journal of Educational Technology, 40(1), 32-41.

Jopling, M. (2012). 1:1 online tuition: a review of the literature from a pedagogical perspective. Journal of Computer Assisted Learning, 28(4), 310-321.

Jorge, I. (2011). The influence of the e-tutor on the development of collaborative critical thinking in a students' e-forum: association levels with Cramer's V. Proceedings of the International Joint Conference and Media Day. Aveiro: Universidade de Aveiro

Oliver, R.L. (1999). Whence consumer loyalty?, Journal of Marketing, 63, 33-44.

Pinder, P.J. (2008). Exploring and understanding the benefits of tutoring software on urban students' science achievement: what are Baltimore city practitioners' perspectives? Regional Eastern Educational Research Association Conference, SC.

Prensky, M. (2003). e-Nough! On The Horizon, 11(1), 1-14, MCB University Press.

Shee, D., \& Wang, Y. (2008). Multi-criteria evaluation of the web-based e-learning system: A methodology based on learner satisfaction and its applications. Computers \& Education, 50(3), 894-905.

Siritongthaworn, S. \& Krairit, D. (2006). Satisfaction in E-learning: the Context of Supplementary Instruction, Campus-Wide Information, 23(2), 76-92. 


\section{Appendix}

\begin{tabular}{|c|c|c|c|c|c|c|c|c|c|c|c|c|}
\hline \multirow[b]{2}{*}{$\begin{array}{l}\text { 1. Circle the number that } \\
\text { indicates how many } \\
\text { times you used e- } \\
\text { tutoring in ancient } \\
\text { Greek. }\end{array}$} & 0 & 1 & 2 & 3 & 4 & 5 & 6 & 7 & 8 & 9 & 10 & 11 \\
\hline & 12 & 13 & 14 & 15 & 16 & 17 & 18 & 19 & 20 & 21 & 22 & \\
\hline \multirow{2}{*}{$\begin{array}{l}\text { 2. Circle the number that } \\
\text { indicates how many } \\
\text { times you used e- } \\
\text { tutoring in } \\
\text { Mathematics. }\end{array}$} & 0 & 1 & 2 & 3 & 4 & 5 & 6 & 7 & 8 & 9 & 10 & 11 \\
\hline & 12 & 13 & 14 & 15 & 16 & 17 & 18 & 19 & 20 & 21 & 22 & \\
\hline
\end{tabular}

3. If you circled zero (0) in the two previous questions, now circle YES or NO, so as to demonstrate the reason for not using e-tutoring.

\begin{tabular}{|l|c|c|}
\hline A. I didn't have a computer at home. & YES & NO \\
\hline $\begin{array}{l}\text { B. I faced technical problems I couldn't solve and I couldn't use } \\
\text { e-tutoring }\end{array}$ & YES & NO \\
\hline C. I didn't need it in ancient Greek. & YES & NO \\
\hline D. I didn't need it in Mathematics. & YES & NO \\
\hline E. I didn't have time to use e-tutoring. & YES & NO \\
\hline F. I didn't like it. & YES & NO \\
\hline G. Other (please specify): & \multicolumn{2}{|l}{} \\
\hline
\end{tabular}

\begin{tabular}{|c|c|c|c|c|c|c|}
\hline & Excellent & Very good & Good & Average & Poor & Very poor \\
\hline 4. Knowledge of computer use & & & & & & \\
\hline 5. Knowledge of Internet use & & & & & & \\
\hline 6. Grade & \multicolumn{3}{|c|}{ First Gymnasio } & \multicolumn{3}{|c|}{ Second Gymnasio } \\
\hline 7. Gender & \multicolumn{3}{|c|}{ Female } & \multicolumn{3}{|c|}{ Male } \\
\hline 8. I have a Facebook account & \multicolumn{3}{|c|}{ YES } & \multicolumn{3}{|c|}{ NO } \\
\hline 9. I use Skype & \multicolumn{3}{|c|}{ YES } & \multicolumn{3}{|c|}{$\mathrm{NO}$} \\
\hline
\end{tabular}

Choose the level of your agreement with the sentences below (I totally agree, I agree, I neither agree nor disagree, I disagree, I totally disagree, I do not know/no answer).

10. I use microphone and text during e-tutoring.

11. I use exclusively microphone during e-tutoring.

12. I use exclusively text during e-tutoring.

13. The e-tutoring environment provides the tools I needed for the course.

14. I am satisfied with the easy use of e-tutoring.

15. The e-tutoring environment is friendly.

16. During the use of e-tutoring I didn't face technical problems.

17. The e-tutoring is a safe working environment.

18. At e-tutoring the teachers provide material that meets my needs.

19. At e-tutoring the teachers provide sufficient material.

20. At e-tutoring the teachers provide additional material to the one provided in the classroom.

21. E-tutoring corresponds to my demands.

22. E-tutoring makes discussion with the educator easy. 
$7^{\text {th }}$ International Conference in Open \& Distance Learning - November 2013, Athens, Greece - PROCEEDINGS

23. E-tutoring helps me control the progress of my learning.

24. E-tutoring helps me learn the material taught.

25. E-tutoring makes discussion with other students easy.

26. I liked watching video from an e-tutoring course.

27. E-tutoring provides individualized support of learning.

28. I learned and had fun with e-tutoring.

29. Overall, I am satisfied with e-tutoring.

30. Overall, e-tutoring is successful.

31. Write whatever else you deem necessary. 